\title{
Influence of microwave processing on the bioactive compounds, antioxidant activity and sensory acceptance of blackberry jelly
}

\author{
Paula Nogueira CURI ${ }^{1}$, Derlyene Lucas SALGADO ${ }^{2}$, Kamila MENDONÇA², Rafael PIO ${ }^{1}$, \\ Jefferson Luiz Gomes FERREIRA², Vanessa Rios de SOUZA ${ }^{2 *}$ (i)
}

\begin{abstract}
The purpose of this study was to evaluate the effect of microwave and microwave combined with vacuum on the nutritional and sensory characteristics of blackberry jelly, in order to verify if they are actually more viable methods of processing when compared to the traditional process in open pan. It was verified that the processing methods studied did not influence the sensory characteristics of the obtained jelly, however, it was observed that the microwave processing, in particular low power microwave without vacuum, promotes smaller nutritional losses in the blackberry jelly. The jellies processed in low-power microwave without vacuum stood out from the others presenting the highest antioxidant activity by DPPH $(2095.19 \mathrm{~g}$ f.w./g of DPPH) and ABTS method (21.81 $\mu \mathrm{M}$ trolox/g), the highest total phenolic content (504.58 mg GAE/100 $\mathrm{g}$ ) and one of the highest ascorbic acid content $(33.72 \mathrm{mg}$ ascorbic acid/100 g). The jelly processed in high-power microwave without vacuum, stood out to have the highest antioxidant activity by the beta-carotene method ( $84.20 \%$ protection). In relation to the anthocyanins content, the jellies processed by vacuum microwave (low and high power) were highlighted because they presented the highest levels (16.25 and $15.03 \mathrm{mg}$ of cyanidin equivalent 3 glucoside/100g, respectively).
\end{abstract}

Keywords: jelly; processing; nutritional; microwave.

Practical Application: Microwave processing can be an option of processing jelly to obtain more nutritionally rich products.

\section{Introduction}

The consumption of berries has increased in recent years due to their pleasant sensorial characteristcs and nutritional quality, presenting beneficial health properties due to the their nutritional richiness (Seeram, 2008; Souza et al., 2014a; Guedes et al., 2017). Due to the fragility and high postharvest respiration rate, these fruits are generally converted into frozen, dried and canned products or processed into jellies and juices for longer storage (Souza et al., 2014b, 2015). Heat is highly utilized in the food industry in a number of operations, both processing and conservation, however it may have a negative effect on food characteristics causing undesirable sensorial and nutritional changes (Souza et al., 2015). There are several studies demonstrating that during the berry fruit jelly processing the heat can cause losses up to $70 \%$ of phenolic compounds, $90 \%$ of anthocyanin, $80 \%$ of vitamin C and up to $73 \%$ of the antioxidant activity (Kovačević et al., 2009; Wu et al., 2010; Souza et al., 2015).

To counteract those undesirable changes, over a course of centuries, various food processing technologies, known as novel or emerging technologies, have been explored and implemented to provide safe, fresher-tasting and nutritive food products (Misra et al., 2017). There are a substantial number of studies in the literature comparing the effect of emerging technologies such as dielectric microwave heating (Gonçalves et al., 2013), ohmic heating (Cappato et al., 2018), ultrasound (Ribeiro et al., 2017; Monteiro et al., 2018), high hydrostratic pressure (Spira et al., 2018) among others with the traditional thermal treatment on nutritional and sensory charcateristics in a variety of foods.
The jelly microwave processing can be an interesting processing option because, due to the faster heating, the product will be less exposed time to heat (Leonelli et al., 2013). The microwaves are absorbed by the water molecules, sugars and fats contained in the food and so the heat is generated inside the product causing less sensorial and nutritional losses (Espinosa et al., 2017; Martins et al., 2019). The vacuum is another technique that can contribute to minimizing the oxidation reactions during the processing, since the process occurs in the absence of oxygen (Araújo, 2004). Studies showed that the microwave and vacuum were effective in the processing of some products demonstrating that these technologies effectively minimized nutritional changes (Espinosa et al., 2017; Horuz et al., 2017).

Based on that, the aim of this work was to evaluate the effect of microwave and microwave combined with vacuum on the nutritional and sensory characteristics of blackberry jelly, in order to verify if they are actually more viable methods of processing when compared to the traditional process in open pan.

\section{Materials and methods}

\subsection{Samples}

It was used blackberry of Brazos cultivar, 2016/2017 crop, obtained from the Federal University of Lavras - UFLA, Temperate Rainy Weather (Lavras/MG - Brazil). At their physiological maturity, based on colour and size, the fruits were harvested 
in the morning and were immediately processed. Besides the fruits, sucrose and high methoxyl pectin (Danisco, SP, Brazil) were also used in the jelly processing.

\subsection{Preparation of jellies}

The preparation of the jelly was performed at the Laboratory of Vegetable Products Processing - DCA/UFLA. After thawing at room temperature and discarding the fruits with physical and microbiological damages, the blackberry fruits were ground with 1:1 water in a Walita RI2094/01750W blender at full speed. Thereafter the obtained pulp was finely sieved to give the clarified juice. The percentages of the ingredients used to prepare the jellies were: $60 \%$ clarified blackberry juice, $38.5 \%$ sucrose and $1.5 \%$ high methoxylation pectin.

For the preparation of the conventional jelly, 200 grams of juice containing the sugar was heated by a gas flame in an open pan. After boiling, the high methoxylation pectin was added. At the end of the process, when the soluble solids reached $65{ }^{\circ} \mathrm{Brix}$, the heating was stopped. A portable refractometer model RT-82 was used to measure the soluble solids The hot jellies were poured into $250 \mathrm{~mL}$ capacity sterilized glass vials and stored at a temperature of $7{ }^{\circ} \mathrm{C}$ until analysis. The processing time was 35 minutos.

For the preparation of the jellies in microwave, a mixture of 200 grams of juice containing the sugar and the pectin was taken to the microwave. Four microwave formulations were processed, varying potency and presence/absence of vacuum:

- microwave low power - 0.53 Watts/gram [W/g] without vacuum;

- microwave low power - 0.53 Watts/gram [W/g] under vacuum at $300 \mathrm{mmHg}$;

- high power microwave - 2.80 Watts/gram [W/g] without vacuum;

- high power microwave - 2.80 Watts/gram [W/g] under vacuum at $300 \mathrm{mmHg}$.

The low power jelly was processed for a period of 25 minutes and the high potency for a period of 4.5 minutes, these were the required times for the jellies reach $65^{\circ} \mathrm{Brix}$ - determined in pre-tests. This processing was done in microwave conventional Eletrolux model Blue Touch MEC 41 adapted vacuum.

The antioxidante activity (DPPH, ABTS, Beta carotene), total phenolics, anthocyanin and ascorbic acid in the fruit and in all jelly formulations (a traditional sample and the 4 samples processed in microwaves) were analyzed.

\subsection{Analysis}

\section{Extraction procedure}

The sample extraction was performed first with methanol/water (50:50, $\mathrm{v} / \mathrm{v})$ and then with acetone/water (70:30, $\mathrm{v} / \mathrm{v}$ ) following the method described by Larrauri et al. (1997). Five grams of sample were used to the total volume of $50 \mathrm{~mL}$ of solvents and distilled water.

\section{Antioxidant activity - DPPH}

According to the described method by Brand-Williams et al. (1995), the sample extracts in methanol were mixed with the DPPH (2,2- diphenyl-1-picrylhydrazyl) radical solution. The reduction of this radical by the antioxidant constituents present in the sample was measured trough the absorbance decrease at $517 \mathrm{~nm}$, using a spectrophotometer (Ultrospec 2000 Pharmacia Bioteche, Cambridge, England). The result was showed as $\mathrm{EC}_{50}$ (f.w./g of DPPH).

\section{Antioxidant activity - ABTS}

The antioxidant activity was measured following the method described by Re et al. (1999). Briefly, the absorbance decrease at $734 \mathrm{~nm}$, using a spectrophotometer (Ultrospec 2000 Pharmacia Bioteche, Cambridge, England), was measured after sample reaction with the ABTS radical cation. For calibration, Trolox ethanolic solutions were used. The results were presented as micromoles of Trolox equivalents (TEs) per gram of fresh weight ( $\mu \mathrm{mol}$ of TEs/g of f.w.).

\section{Antioxidant activity - $\beta$-carotene}

The antioxidante activity ( $\beta$-carotene metod) procedure followed the described by Marco (1968). Briefly, after mixing the $\beta$-carotene/linoleic acid system with the properly diluted extract samples or with the Trolox standard (control), the tubes were incubated at $40{ }^{\circ} \mathrm{C}$ and the absorbance at $470 \mathrm{~nm}$ was measured using a spectrophotometer (Ultrospec 2000 Pharmacia Bioteche, Cambridge, England). The results were expressed as $\%$ of protection (Equation 1-3)

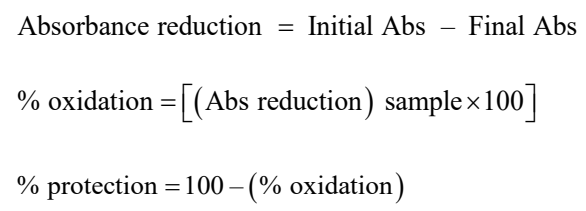

\section{Total phenolic}

According to the Folin-Ciocalteu method described by Singleton et al. (1999), after mixing the sample extracts with Folin-Ciocalteu reagent and saturated sodium carbonate solution, the tubes were incubated at $37^{\circ} \mathrm{C}$ and the developed colour was measures at $750 \mathrm{~nm}$ using a spectrophotometer (Ultrospec 2000 Pharmacia Bioteche, Cambridge, England). For calibration, aqueous solutions of gallic acid were used. The results were expressed in g gallic acid equivalents (GAE)/100 g.

\section{Total monomeric anthocyanin content}

The anthocyanin content was determined following the $\mathrm{pH}$ differential method previous described by Wrolstad (1976). After diluting each sample extract in buffer solution $(\mathrm{pH} 1.0$ and $\mathrm{pH} 4.5$ ), tthe absorbance of the solutions was measured at 510 and $700 \mathrm{~nm}$ using a spectrophotometer (Ultrospec 2000 Pharmacia Bioteche, Cambridge, England). The TMAC (expressed in terms of cyanidin-3-glucoside) was calculated according to the Equations 4 and 5. 
$\mathrm{A}=\left(\mathrm{A}_{510}-\mathrm{A}_{700}\right)_{\mathrm{pH} 1.0}-\left(\mathrm{A}_{510}-\mathrm{A}_{700}\right)_{\mathrm{pH} 4.5}$

TMA content $=(\mathrm{A} \times \mathrm{MW} \times \mathrm{DF} \times \mathrm{Ve} \times 1000) /(\varepsilon \times 1 \times \mathrm{M})$

where: MW is the molecular weight of cyanidin-3-glucoside ( $\left.449 \mathrm{~g} \mathrm{~mol}^{-1}\right)$; DF is the dilution factor; Ve is the extract volume; $\varepsilon$ is the molar extinction coefficient of cyanidin-3-glucoside $(29,600)$; and $M$ is the mass of the berries extracted.

The results were expressed as mg cyanidin-3-glucoside equivalents/100 $\mathrm{g}$ of FW.

\section{Ascorbic acid}

The colorimetric method with 2,4-dinitrophenylhydrazine (2,4-DNPH) was used to determine the ascorbic acid content (Strohecker \& Henning, 1967). The absorbance readings were done at $520 \mathrm{~nm}$ using a spectrophotometer (Ultrospec 2000 Pharmacia Bioteche, Cambridge, England). The results were expressed in mg ascorbic acid/100 g of fresh weight.

\subsection{Sensory analysis}

The acceptance test was performed in individual booths under white light by 90 consumers ( 50 women and 40 men) who were students and university employees aged between 18 and 40 years. The consumers were selected based on their regular consumption of jam and jelly products to ensure that they were the target audience. The blackberry jam samples were evaluated for acceptance in relation to the attributes appearance, taste, consistency and overall impression, using a nine-point structured hedonic scale varying between the hedonic terms "extremely disliked" and "extremely liked" (Stone \& Sidel, 1993). The tasters received $10 \mathrm{~g}$ of each sample in disposable plastic cups coded with three-digit numbers, which were served monadically, following the order of presentation according to the experimental design for evaluation of treatments proposed by Wakeling \& Macfie (1995). samples. The sensory analyses were performed according to the Ethics Committee of the Federal University of Lavras, approval number 422.634 .

\subsection{Statistic analysis}

The sensory acceptance, bioactive compounds and antioxidant activity data of blackberry jellies obtained from different processing methods were evaluated through analysis of variance and Tukey mean test. For a better understanding and visualization of the samples evaluated, a principal componente analysis - PCA was obtained for the nutritional characteristics and a three-way internal preference map - PARAFAC was plotted for the sensory data (Granato et al., 2018).

For the PCA, the data set was arranged in a matrix of 5 lines (samples) and 6 columns (bioactive compounds and antioxidant activity). Regarding the PARAFAC a three-way array was arranged from staked matrices of 5 lines (samples) and 90 columns (consumers) of each acceptance attribute. Both data set were previously standardized (correlation matrix). Data analysis was performed using Sensomaker software version 1.9.1 (Pinheiro et al., 2013).

\section{Results and discussion}

\subsection{Bioactive compounds and antioxidant activity}

The bioactive compounds and the antioxidant activity of the fresh blackberry and the jellies formulations processed in the open pan and by microwaves are shown in Table 1. To facilitate the visualization among the jelly samples is shown in Figure 1 the PCA - Principal Components Analysis.

It was observed a significant difference $(p \leq 0.05)$ for all variables analyzed as antioxidant activity by the ABTS, DPPH and beta carotene methods, total phenolic content, anthocyanins and ascorbic acid that is, it can be verified that the type of processing has an influence on the degradation of nutritional compounds (Table 1).

According to the PCA (Figure 1) and the average table (Table 1) it can be verified that jellies processed in low-power microwave without vacuum stood out from the others presenting the highest antioxidant activity by the DPPH method (2095.19 f.w./g of DPPH) and by the ABTS method $(21.81 \mu \mathrm{M}$ trolox/g), the highest total phenolic content (504.58 mg GAE/100 g) and one of the highest ascorbic acid content (33.72 $\mathrm{mg}$ ascorbic acid/100 g) (Table 1 and Figure 1). The jelly processed in high-power microwave

Table 1. Antioxidant capacity (DPPH, ABTS and beta-carotene), total phenolic, anthocyanin and ascorbic acid in fresh blackberry and the different jelly formulations.

\begin{tabular}{|c|c|c|c|c|c|c|}
\hline Samples & $\begin{array}{l}\text { Antioxidant } \\
\text { Capacity - } \\
\text { DPPH }\end{array}$ & $\begin{array}{c}\text { Antioxidant } \\
\text { Capacity - } \\
\text { ABTS }\end{array}$ & $\begin{array}{c}\text { Antioxidant } \\
\text { Capacity Beta - } \\
\text { carotene }\end{array}$ & Total Phenolic & Anthocyanin & Ascorbic Acid \\
\hline Fresh blackberry & 1993.95 & 32.56 & 85.88 & 892.52 & 20.80 & 93.13 \\
\hline Open Pan Jelly & $4009.82^{\mathrm{b}}$ & $17.85^{\mathrm{c}}$ & $82.52^{\mathrm{ab}}$ & $485.73^{\mathrm{b}}$ & $12.76^{\mathrm{ab}}$ & $32.04^{\mathrm{a}}$ \\
\hline Low power microwave jelly & $2095.19^{\mathrm{d}}$ & $21.81^{\mathrm{a}}$ & $81.29^{\mathrm{b}}$ & $504.58^{\mathrm{a}}$ & $11.10^{\mathrm{b}}$ & $33.72^{\mathrm{a}}$ \\
\hline High power microwave jelly & $3070.29^{c}$ & $19.60^{\mathrm{b}}$ & $84.20^{\mathrm{a}}$ & $303.33^{c}$ & $12.67^{\mathrm{ab}}$ & $20.68^{\mathrm{bc}}$ \\
\hline Low power vacum microwave jelly & $4070.29^{\mathrm{a}}$ & $19.48^{\mathrm{b}}$ & $48.28^{\mathrm{d}}$ & $302.29^{c}$ & $16.23^{\mathrm{a}}$ & $21.89^{\mathrm{b}}$ \\
\hline High power vacum microwave jelly & $4000.45^{\mathrm{b}}$ & $17.86^{\mathrm{c}}$ & $56.00^{c}$ & $293.64^{c}$ & $15.03^{\mathrm{a}}$ & $18.30^{c}$ \\
\hline
\end{tabular}

Means followed by the same letter do not differ statistically among each other ( $\mathrm{p}>0.05$; Tukey test). Abbreviations: DPPH = elimination activity of 2-diphenyl-1-picrihydrazyl radicals; Total phenolics (mg GAEs/100 g fw); Antioxidant capacity - DPPH (EC ${ }_{50}$ - f.w./g of DPPH); Antioxidant capacity - ABTS ( $\mu$ M trolox/g f.w.); Ascorbic acid (mg/100 g f.w.), Beta carotene (\% protection); Total anthocyanin (mg of cyanidin 3-glucoside equivalent/100 $\mathrm{g}$ of f.w.). 
without vacuum, stood out to have the highest antioxidant activity by the beta-carotene method ( $84.20 \%$ protection). In relation to the anthocyanins content, it can be seen from Table 1 and Figure 1 that the jellies processed by vacuum microwave (low and high power) were highlighted because they presented the highest levels (16.25 and $15.03 \mathrm{mg}$ of cyanidin equivalent 3 glucoside/100 g, respectively).

There are no studies in the literature on the use of microwaves as a jelly processing method, however, several studies involving the use of microwave in the most diverse applications and products have shown that this technique is promising and can minimize the nutritional degradations of the products. According to Flores (2017), the use of microwave in the products development is promising, thus maintaining higher concentrations of antioxidants, being one of its main advantages the application of reduced times. Devece et al. (1999) demonstrated that the use of microwave in the mushrooms bleaching promotes a lower loss of the antioxidant compounds when compared to the traditional heat treatment. In Cuastumal et al. (2016) studies, it was found that the heat treatment promotes a significant loss of vitamin $\mathrm{C}$ in tropical fruits, while the microwave practically does not affect

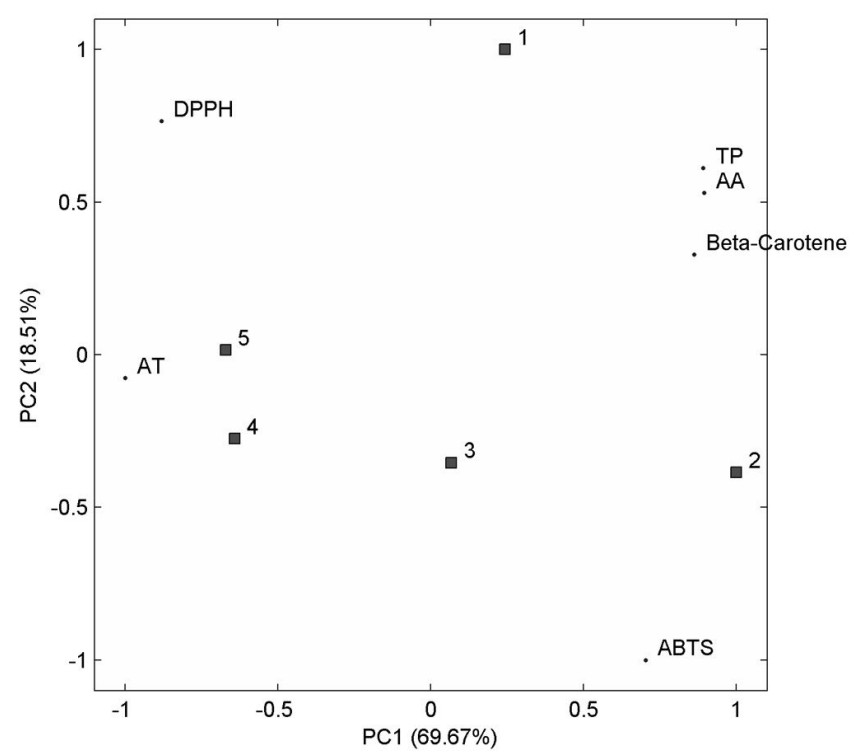

Figure 1. Principal Components Analysis for antioxidant capacity (DPPH, ABTS and beta carotene), total phenolics (TP), anthocyanin (AT) and ascorbic acid (AA) for the different formulations of mulberry jam. 1 = Open Pan Jelly; 2 = Low power microwave jelly; 3 = High power microwave jelly; 4 = Low power microwave jelly with vacum $(300 \mathrm{mmHg}) ; 5=$ High power microwave jelly with vacum $(300 \mathrm{mmHg})$. the original content. In studies comparing the conventional heat treatment with the microwave in kiwi puree, it was shown that microwave heating were more effective at enzyme inactivation and antioxidant capacity retention than the conventional thermal treatment (Benlloch-Tinoco et al., 2013).

According to the presented data, the nutritional advantage of the use of the microwave or vacuum microwave for processing the jelly is clear. This is because, for all the characteristics, the microwave had an advantage over the processing in open pan. In general, the processing that gave origin to the most nutritionally rich jelly was the low power microwaves without the use of vacuum. Thus, the conventional open-pan substitution by the microwave processing is advised, although more studies are needed to determine the appropriate power and and whether or not vacuum should be applied, in industrial application. Although the cost of microwave implementation may be higher than the open pan, the nutritional advantage and shorter processing time overlap with this disadvantage.

\subsection{Sensory characteristics}

Table 2 shows the average notes of the sensorial attributes evaluated for the jelly produced in the open pan and for the jellies produced by microwaves. In order to facilitate visualization, Figure 2 shows the three-way internal preference map - PARAFAC, where the evaluated samples, the sensory attributes and the consumers have been distributed.

According to Table 2, it can be verified that, except for the consistency, no significant difference $(p>0.05)$ was observed between the jelly samples. All samples showed high sensory acceptance, with averages varying between the hedonic terms "liked slightly" and "liked very much". This similar sensory acceptance among the blackberry jam samples can be visualized on the three-way internal preference map (Figure 2).

Regarding the sensorial characteristics it is clear that the conventional processing does not differentiate from the preparation by microwave and microwaves ie the sensory characteristics of the jelly were not influenced by the different types of processing evaluated. Thus, microwave processing may still be more advantageous than open pan processing because it has a shorter processing time.

Based on the results obtained, this work clear demonstrates the microwave potential for jelly processing, since it can minimizes nutritional degradation and reduces the processing time. After deeper and further studies, this innovative processing could be implemented by the food industry in order to reduce the damages caused by the heat and consequently to obtain higher quality products, meet ing the consumer demand.

Table 2. Sensory characteristics for blackberry jelly obtained by different types of processing.

\begin{tabular}{|c|c|c|c|c|}
\hline Processing methods & Color & Taste & Consistency & Overall Liking \\
\hline Open Pan Jelly & $7.62^{\mathrm{a}}$ & $7.14^{\mathrm{a}}$ & $6.44^{\mathrm{b}}$ & $6.97^{\mathrm{a}}$ \\
\hline Low power microwave jelly & $7.86^{\mathrm{a}}$ & $7.12^{\mathrm{a}}$ & $7.07^{\mathrm{ab}}$ & $7.22^{\mathrm{a}}$ \\
\hline High power microwave jelly & $7.72^{\mathrm{a}}$ & $7.33^{\mathrm{a}}$ & $7.15^{\mathrm{a}}$ & $7.28^{\mathrm{a}}$ \\
\hline Low power vacum microwave jelly & $7.77^{\mathrm{a}}$ & $7.17^{\mathrm{a}}$ & $7.01^{\mathrm{ab}}$ & $7.29^{\mathrm{a}}$ \\
\hline High power vacum microwave jelly & $7.89^{\mathrm{a}}$ & $7.29^{\mathrm{a}}$ & $7.27^{\mathrm{a}}$ & $7.38^{\mathrm{a}}$ \\
\hline
\end{tabular}

The mean values with the same lowercase letters in the column indicate that there is no significant difference between the samples ( $\mathrm{p} \leq 0.05$ ) from the Tukey test. 


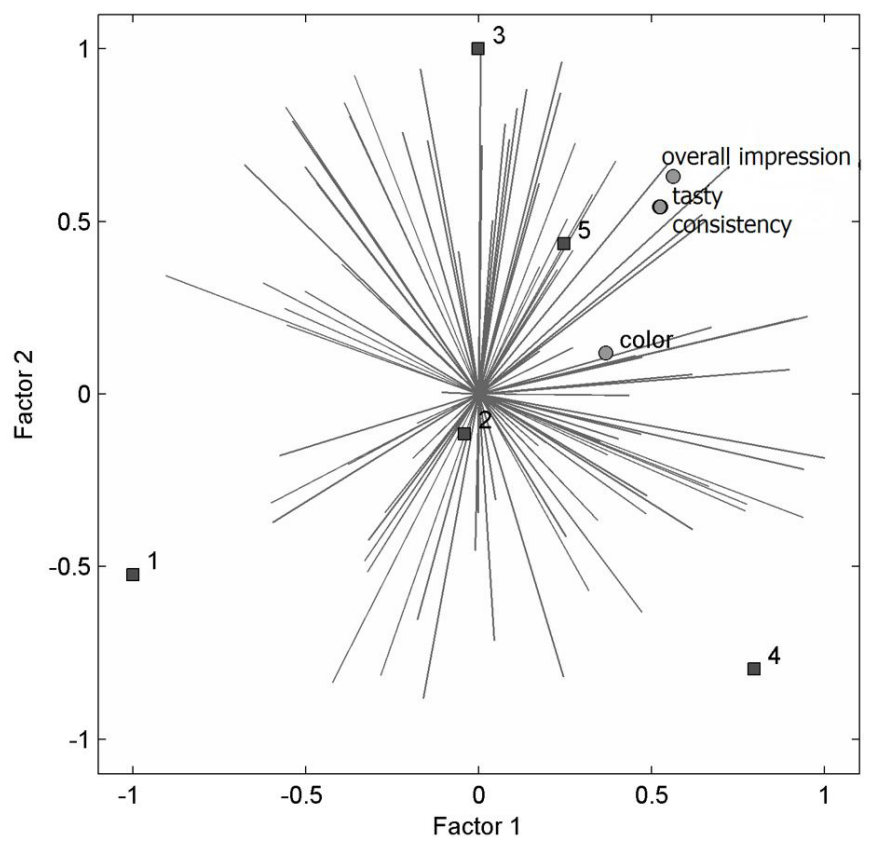

Figure 2. Three-way internal preference map (PARAFAC) for color, taste, consistency and overall impression for the different formulations of blackberry jam. 1 = Open Pan Jelly; 2 = Low power microwave jelly; 3 = High power microwave jelly; $4=$ Low power microwave jelly with vacum $(300 \mathrm{mmHg}) ; 5$ = High power microwave jelly with vacum (300 $\mathrm{mmHg}$ ).

\section{Conclusions}

In this study, it was observed that the processing method (open pan, microwave or vacuum microwave) has no influence on the sensory characteristics of the obtained blackberry jelly, however, the microwave processing, in particular low power microwave without vacuum, promotes lower nutritional losses compared to conventional open pan processing. In this way, microwave processing can be an option of processing jelly to obtain more nutritionally rich products. In addition, the microwave allows to process the products in a shorter processing time which can offset the longer-term investment the greater the initial investment.

\section{Acknowledgements}

To CAPES, CNPq and FAPEMIG for the financial support.

\section{References}

Araújo, J. M. A. (2004). Química de alimentos: teoria e prática (3. ed.). Viçosa: UFV.

Benlloch-Tinoco, M., Igual, M., Rodrigo, D., \& Martínez-Navarrete, N. (2013). Comparison of microwaves and conventional thermal treatment on enzymes activity and antioxidant capacity of kiwifruit puree. Innovative Food Science \& Emerging Technologies, 19, 166-172. http://dx.doi.org/10.1016/j.ifset.2013.05.007.

Brand-Williams, W., Cuvelier, M. E., \& Berset, C. (1995). Use of a free-radical method to evaluate antioxidant activity. Food Science and Technology, 28(1), 25-30. http://dx.doi.org/10.1016/S00236438(95)80008-5.
Cappato, L. P., Ferreira, M. V. S., Moraes, J., Pires, R. P. S., Rocha, R. S., Silva, R., Parente, R. No., Tavares, M. I. B., Freitas, M. Q., Rodrigues, F. N., Calado, V. M. A., Raices, R. S. L., Silva, M. C., \& Cruz, A. G. (2018). Whey acerola-flavoured drink submitted Ohmic Heating: bioactive compounds, antioxidant capacity, thermal behavior, water mobility, fatty acid profile and volatile compounds. Food Chemistry, 263, 81-88. http://dx.doi.org/10.1016/j.foodchem.2018.04.115. PMid:29784332.

Cuastumal, H. G., Ledesma, M. A., \& Ordoñez, L. E. (2016). Vitamina C y color superficial en tomate y pimentón verde efecto de los tratamientos térmicos. Entre Cie e Ingen, 10(20), 123-131.

Devece, C., Rodríguez-López, J. N., Fenoll, L. G., Tudela, J., Catalá, J. M., De los Reyes, E., \& García-Cánovas, F. (1999). Enzyme inactivation analysis for industrial blanching applications: comparison of microwave, conventional, and combination heat treatments on mushroom polyphenoloxidase activity. Journal of Agricultural and Food Chemistry, 47(11), 4506-4511. http://dx.doi.org/10.1021/ jf981398+. PMid:10552842.

Espinosa, W. E., Garzón, L. C. A., \& Medina, O. J. (2017). Microwaveassisted extraction in dry fruit of andean species Vaccinium meridionale: experimental conditions on the recovery of total polyphenols. Ciência e Agrotecnologia, 41(6), 701-712. http://dx.doi. org/10.1590/1413-70542017416016117.

Flores, E. (2017). Extracción de antioxidantes de las bayas del sauco (Sambucus nigra L. subsp. peruviana) con ultrasonido, microondas, enzimas y maceración para la obtención de zumos funcionales. Información Tecnológica, 28(1), 121-132. http://dx.doi.org/10.4067/ S0718-07642017000100012.

Gonçalves, L. C. P., Di Genova, B. M., Dörr, F. A., Pinto, E., \& Bastos, E. L. (2013). Effect of dielectric microwave heating on the color and antiradical capacity of betanin. Journal of Food Engineering, 118(1), 49-55. http://dx.doi.org/10.1016/j.jfoodeng.2013.03.022.

Granato, D., Putnik, P., Kovačević, D. B., Santos, J. S., Calado, V., Rocha, R. S., Cruz, A. G. D., Jarvis, B., Rodionova, O. Y., \& Pomerantsev, A. (2018). Trends in chemometrics: food authentication, microbiology, and effects of processing. Comprehensive Reviews in Food Science and Food Safety, 17(3), 663-677. http://dx.doi.org/10.1111/15414337.12341.

Guedes, M. N. S., Pio, R., Maro, L. A. C., Lage, F. F., Abreu, C. M. P., \& Saczk, A. A. (2017). Antioxidant activity and total phenol content of blackberries cultivated in a highland tropical climate. Acta Scientiarum. Agronomy, 39(1), 43-48. http://dx.doi.org/10.4025/ actasciagron.v39i1.28413.

Horuz, E., Bozkurt, H., Karataş, H., \& Maskan, M. (2017). Effects of hybrid (microwave-convectional) and convectional drying on drying kinetics, total phenolics, antioxidant capacity, vitamin C, color and rehydration capacity of sour cherries. Food Chemistry, 230(1), 295-305. http://dx.doi.org/10.1016/j.foodchem.2017.03.046. PMid:28407914.

Kovačević, D. B., Levaj, B., \& Dragovic-Uselac, V. (2009). Free radical scavenging activity and phenolic content in strawberry fruit and jam. Agriculturae Conspectus Scientificus, 74(3), 155-159.

Larrauri, J. A., Ruperez, P., \& Saura-Calixto, F. (1997). Effect of drying temperature on the stability of polyphenols and antioxidant activity of red grape pomace peels. Journal of Agricultural and Food Chemistry, 45(4), 1390-1393. http://dx.doi.org/10.1021/jf960282f.

Leonelli, C., Veronesi, P., \& Cravotto, G. (2013). Microwave-assisted extraction: an introduction to dielectric heating. In F. Chemat \& G. Cravotto (Eds.), Microwave-assisted extraction for bioactive compounds: theory and practice (pp. 1-14). New York: Springer. 
Marco, G. I. (1968). Rapid method for evaluation of antioxidants. Journal of the American Oil Chemists' Society, 45(9), 594-598. http://dx.doi. org/10.1007/BF02668958.

Martins, C. P. C., Cavalcanti, R. N., Couto, S. M., Moraes, J., Esmerino, E. A., Silva, M. C., Raices, R. S. L., Gut, J. A. W., Ramaswamy, H. S., Tadini, C. C., \& Cruz, A. G. (2019). Microwave processing: current background and effects on the physicochemical and microbiological aspects of dairy products. Comprehensive Reviews in Food Science and Food Safety, 18(1), 67-83. http://dx.doi.org/10.1111/1541-4337.12409.

Misra, N. N., Koubaa, M., Roohinejad, S., Juliano, P., Alpas, H., Inácio, R. S., Saraiva, J. A., \& Barba, F. (2017). Landmarks in the historical development of twenty first century food processing technologies. Food Research International, 97, 318-339. http://dx.doi.org/10.1016/j. foodres.2017.05.001. PMid:28578057.

Monteiro, S. H. M. C., Silva, E. K., Alvarenga, V. O., Moraes, J., Freitas, M. Q., Silva, M. C., Raices, R. S. L., Sant'Ana, A. S., Meireles, A. A., \& Cruz, A. G. (2018). Effects of ultrasound energy density on the non-thermal pasteurization of chocolate milk beverage. Ultrasonics Sonochemistry, 42, 1-10. http://dx.doi.org/10.1016/j. ultsonch.2017.11.015. PMid:29429649.

Pinheiro, A. C. M., Nunes, C. A., \& Vietoris, V. (2013). SensoMaker: a tool for sensorial characterization of food products. Ciência $e$ Agrotecnologia, 37(3), 199-201. http://dx.doi.org/10.1590/S141370542013000300001.

Re, R., Pellegrini, N., Proteggente, A., Pannala, A., Yang, M., \& RiceEvans, C. (1999). Antioxidant activity applying an improved ABTS radical cation decolorization assay. Advances in Free Radical Biology \& Medicine, 26(9-10), 1231-1237. http://dx.doi.org/10.1016/S08915849(98)00315-3. PMid:10381194.

Ribeiro, M. M., Valdramidis, V. P., Nunes, C. A., \& Souza, V. R. (2017). Synergistic effect of thermosonication to reduce enzymatic activity in coconut water. Innovative Food Science \& Emerging Technologies, 41, 404-410. http://dx.doi.org/10.1016/j.ifset.2017.04.013.

Seeram, N. P. (2008). Berry fruits: compositional elements, biochemical activities, and the impact of their intake on human health, performance, and disease. Journal of Agricultural and Food Chemistry, 56(3), $627-$ 629. http://dx.doi.org/10.1021/jf071988k. PMid:18211023.

Singleton, V. L., Orthofer, R., \& Lamuela-Raventos, R. M. (1999). Analysis of total phenols and other oxidation substrates and antioxidants by means of Folin-Ciocalteu reagent. Methods in Enzymology, 299, 152-178. http://dx.doi.org/10.1016/S0076-6879(99)99017-1.

Souza, V. R., Pereira, P. A. P., Pinheiro, A. C. M., Lima, L. C. O., Pio, R., \& Queiroz, F. (2014b). Analysis of the subtropical blackberry cultivar potential in jelly processing. Journal of Food Science, 79(9), S1776-S1781. http://dx.doi.org/10.1111/1750-3841.12565. PMid:25154800.

Souza, V. R., Pereira, P. A. P., Teixeira, T. R., Silva, T. L. T., Pio, R., \& Queiroz, F. (2015). Influence of processing on the antioxidant capacity and bioactive compounds in jellies from different blackberry cultivars. International Journal of Food Science \& Technology, 50(7), 1658-1665. http://dx.doi.org/10.1111/ijfs.12819.

Souza, V. R., Silva, T. L., Oliveira, L. C., Pio, R., \& Queiroz, F. (2014a). Determination of the bioactive compounds, antioxidant activity and chemical composition of Brazilian blackberry, red raspberry, strawberry, blueberry and sweet cherry fruits. Food Chemistry, 156, 362-368. http://dx.doi.org/10.1016/j.foodchem.2014.01.125. PMid:24629981.

Spira, P., Bisconsin-Junior, A., Rosenthal, A., \& Monteiro, M. (2018). Effects of high hydrostatic pressure on the overall quality of Pêra-Rio orange juice during shelf life. Food Science \& Technology International, 24(6), 507-518. http://dx.doi.org/10.1177/1082013218768997. PMid:29653495.

Stone, H. S., \& Sidel, J. L. (1993). Sensory evaluation practices. San Diego: Academic Press.

Strohecker, R., \& Henning, H. M. (1967). Analisis de vitaminas: metodos comprobados. Madrid: Paz Montalvo.

Wakeling, I. N., \& Macfie, H. J. H. (1995). Designing consumer trials balanced for first and higher orders of carry-over effect when only a subset of k samples from $t$ may be tested. Food Quality and Preference, 6(4), 299-308. http://dx.doi.org/10.1016/0950-3293(95)00032-1.

Wrolstad, R. E. (1976). Color and pigment analyses in fruit products (Bulletin, No. 624). Corvallis: University Agriculture Experimental Station.

Wu, R., Frei, B., Kennedy, J. A., \& Zhao, Y. (2010). Effects of refrigerated storage and processing technologies on the bioactive compounds and antioxidant capacities of 'Marion' and 'Ever- green' blackberries. Lebensmittel-Wissenschaft + Technologie, 43(8), 1253-1264. http:// dx.doi.org/10.1016/j.lwt.2010.04.002. 